\title{
Sequential Separation of Lysozyme and Ovalbumin from Chicken Egg White
}

\author{
Nalaka Sandun Abeyrathne ${ }^{1}$, Hyun Yong Lee ${ }^{1}$, and Dong Uk Ahn ${ }^{1,2 *}$ \\ ${ }^{1}$ Department of Agricultural Biotechnology, Major in Biomodulation, \\ Seoul National University, Seoul 151-921, Korea \\ ${ }^{2}$ Department of Animal Science, Iowa State University, Ames, IA 50010, USA
}

\begin{abstract}
Lysozyme was trapped from $2 \times$ diluted egg white using Amberlite FPC 3500 ion exchange resin $(1 \mathrm{~g} / 10 \mathrm{~mL}$ of egg white). The lysozyme bound to the resin was recovered using $0.1 \mathrm{~N}$ glycine-NaOH buffers, $\mathrm{pH} 9.0$, containing $0.5 \mathrm{M} \mathrm{NaCl}$. After separating lysozyme, the $\mathrm{pH}$ of the egg white solution was adjusted to 4.75 and centrifuged to remove interfering proteins. The supernatant was collected, added with $2.5 \%$ citric acid and $5.0 \%$ ammonium sulfate combination to precipitate egg white proteins, except for ovalbumin. After centrifugation, both supernatant (S1) and precipitant were collected. The precipitant was dissolved with 4 volumes of distilled water, and then $2.0 \%$ ammonium sulfate and $1.5 \%$ citric acid combinations added, stirred overnight in a cold room, and centrifuged. The resulting supernatant (S2) was pooled with the first supernatant (S1), desalted using an ultrafiltration unit, heat-treated at $70^{\circ} \mathrm{C}$ for $15 \mathrm{~min}$, and then centrifuged. The supernatant was collected as an ovalbumin fraction and lyophilized. The separated proteins were confirmed using Western blotting. The yield of lysozyme and ovalbumin was $>88.9 \%$ and $>97.7 \%$, respectively, and the purity of lysozyme and ovalbumin was $>97 \%$ and $87 \%$, respectively. The results indicated that the protocol was simple, and separated lysozyme and ovalbumin effectively.
\end{abstract}

Key words: ovalbumin, lysozyme, ammonium sulfate, citric acid, egg white, sequential separation

\section{Introduction}

Ovalbumin (54\%) and lysozymes (3.5\%) are among the major proteins in egg white (Stadelman and Cotterill, 2001) that have many functional properties. Ovalbumin is a phosphoglycoprotein with a molecular size of $45 \mathrm{kDa}$ and an iso-electric point of 4.5 (Huopalahtiet al., 2007). Although, the functions of ovalbumin other than nutritional value for humans are not well known, it is widely used in cell culture, and has high potentials to be used as a drug carrier or to produce various functional peptides (Datta et al., 2009). Hydrolyzed peptides derived from ovalbumin showed excellent ACE inhibitory and antihypertensive activities in spontaneously hypertensive rats (Miguel and Aleixandre, 2006; Miguel et al., 2007). Also, hydrolysates of ovalbumin reversed abnormalities associated with metabolic syndromes and reduced oxidative stress in spontaneously hypertensive rats (Manso et al., 2008).

\footnotetext{
*Corresponding author: Dong U. Ahn, Department of Animal Science, Iowa State University, Ames, IA 50011-3150, USA. Tel: 1-515-294-6595, Fax: 1-515-294-9143, E-mail: duahn@, iastate.edu
}

Lysozyme is called an N-Acetyl-muramic-hydrolase and acts as a bacteriolytic enzyme in nature. The molecular weight of lysozyme is $14.4 \mathrm{kDa}$ (Radziejewaska et al., 2008) and has four disulfide bridges with high thermal stability, and its isoelectric point (PI) is 10.7. The World Health Organization (WHO) and many countries allow the use of lysozyme in foods as a preservative. Lysozyme is currently used in kimchi pickles, sushi, Chinese noodles, cheese and wine production (Mine et al., 2004). In nature, there are many forms of lysozyme but egg white lysozyme is among the most soluble and stable protein.

Over the years, various methods have been developed to separate ovalbumin and lysozyme from egg white. Ovalbumin was separated first in early 1900s using saturated ammonium sulfate and acetic acid (Chick and Martin, 1913; Hopkins, 1900). However, the major limitations of the methods were the uncertainty in purity and yield, and the use of extremely high levels of chemicals. Datta et al. (2009) separated a high-purity (98.7\%) ovalbumin using a two-stage polyethersulfone (PES) flat disk membrane. However, the method was very difficult for scaling-up due to the limited capacity of the membrane and the high hydraulic resistance built up during ultrafiltration. Oval- 
bumin was also purified using an electrophoretic method (Desert et al., 2001), foam fractionation (Ward et al., 2007), and a liquid chromatographic method (Awadë and Efstathiou, 1999). Although, these methods showed high purity and yield, none of them were applicable for commercialscale production due to the complexity of the separation procedures and protein denaturation during separation. For the industrial applications of ovalbumin, therefore, developing a simple and effective separation method that can be scaled up is important.

The separation of lysozyme was also developed in the early 1900s. It is one of the first proteins isolated and used. Earlier separation methods for lysozyme from egg white used ammonium sulfate, but the resulting characteristics of lysozyme were altered by $\mathrm{pH}$ changes and salt effects. The lysozyme separated using ammonium sulfate was stable under acidic conditions, but was only partially soluble in alkaline conditions or formed crystals (Alderton et al., 1945). Since the PI value of lysozyme is 10.7, which is the highest among the egg white proteins, ion exchange chromatography was the most commonly used method to separate lysozyme from egg white. Carboxymethyl cellulose (CMC) was used to trap the lysozyme from egg white under alkaline conditions (Strang, 1984). Because of their small particle sizes, however, CMC resin is very difficult to handle when used in batch processes and the flow rate becomes very slow if a column process is used. Recently, CMC magnetic macroporous cellulose was used to isolate lysozyme from chicken egg white. This is one-step separation process and the purity recorded was over $96 \%$ (Safarik et al., 2007). The main limitation of this procedure, however, was scaling up because the price of the resin is very expensive. Non-chromatographic methods such as reductant and thermal treatments have also been tested to separate lysozyme from egg white. Chang et al. (2000) used $\beta$-mercaptoethanol along with other chemicals to separate lysozyme, but $\beta$-mercaptoethanol denatures the protein and cannot be used in foods. Therefore, this method is not practical to separate lysozyme for human applications. Recently, Wan et al. (2006) used ultrafiltration to purify lysozyme from egg white. This method produced lysozyme with more than $80 \%$ purity and yield, but the Aktaprime they used for the purification is applicable only for laboratory scale process.

Since all the methods discussed above have some drawbacks, developing a simple separation method for ovalbumin and lysozyme that can be scaled up is important for the commercial use of the proteins. Also, developing a protocol for two proteins in sequence, instead of one, will provide additional cost-saving benefits. The objective of this study was to develop a sequential separation method for ovalbumin and lysozyme from chicken egg white.

\section{Materials and Methods}

\section{Materials}

Chicken eggs ( $<3$-day-old) were obtained from a local producer and used within a day. Egg white from 10 eggs were pooled in a 1-L beaker, blended at low speed (set at 1) for 2 min using a hand mixer (Kitchen Aid, USA) and used as a replication unit $(n=3)$. Amberlite FPC 3500, ammonium sulfate and citric acid were purchased from Fisher Scientific (Waltham, USA). Lysozyme was purchased from Sigma-Aldrich (USA), and rabbit polyclonal to lysozyme, lysozyme marker HRP and anti-ovalbumin antibody were purchased from Abcam (USA). Rest of the standards and rabbit anti-mouse $\operatorname{IgG}(\mathrm{H}+\mathrm{L})$ conjugated $\mathrm{AP}^{12}$ antibody were purchased from Bio-Rad (USA). Protein content was measured using DC-Protein assay kit (Bio-Rad) after treating egg white with citric acid or acetic acid in combination with ammonium sulfate. Precipitant was dissolved with $2 \mathrm{X}$ distilled water in alkaline $\mathrm{pH}$ and protein content was measured.

\section{Separation of lysozyme using ion exchange resins}

Two hundred eighty $\mathrm{mL}$ of the pooled egg white was transferred to a 1-L beaker, added with 1 volume of distilled water (DW), homogenized at low speed (set at 1) for 2 min using a hand mixer (KitchenAid), and then used to separate lysozyme using cation exchange resins. Carboxymethyl cellulose (CMC) and Ambelite FPC 3500 (Sigma) were tested to compare their performance as a cation exchange resin for lysozyme separation. The resins were equilibrated to $\mathrm{pH} 9.3$ before use. Different amounts of resin $(0.5-2.0 \mathrm{~g} / 10 \mathrm{~mL}$ of egg white) were added to the egg white solution to determine the proper resin: egg white ratio. After adding resin, the sample was continuously stirred overnight using an overhead stirrer (IKA, Model RW 20 DS, Germany) in a $4^{\circ} \mathrm{C}$ cold room. The resin was collected after centrifugation at $3,400 \mathrm{~g}$ at $4^{\circ} \mathrm{C}$ for $15 \mathrm{~min}$, and washed 3-5 times with 5 volumes of distilled water and then $0.1 \mathrm{M}$ glycine- $\mathrm{NaOH}$ buffer, $\mathrm{pH} 9.3$ to remove unbound proteins. The supernatant (lysozyme-free egg white solution) was used to separate ovalbumin in the next step. The lysozyme bound to the resin was eluted with $0.1 \mathrm{M}$ glycine- $\mathrm{NaOH}$ buffer, $\mathrm{pH} 9.3$ containing $0.5 \mathrm{M} \mathrm{NaCl}$. The eluent was collected, desalted and concentrated using ultrafiltration equipped with a $10 \mathrm{kDa}$ cut-off size, hollow fiber 
cartridge (GE healthcare Bio-Sciences Corp. USA), and then lyophilized (Labconco Corp., USA). SDS-PAGE was used to check the separation of lysozyme, and Western blot was used to confirm the separated lysozyme. Yield was determined using the amount of freeze-dried lysozyme recovered. The whole procedure was replicated three times.

\section{Separation of ovalbumin using ammonium sulfate and citric acid combinations}

Separation of ovalbumin was carried out using the method of Abeyrathne et al. (2013) with some modifications. After removing lysozyme, the $\mathrm{pH}$ of lysozyme-free supernatant was adjusted to $\mathrm{pH} 4.75$ with $3 \mathrm{M} \mathrm{HCl}$ and then centrifuged at $3,400 \mathrm{~g}$ for $20 \mathrm{~min}$ at $4^{\circ} \mathrm{C}$ to remove interfering proteins. The resulting supernatant was collected, added with ammonium sulfate and citric acid combination (final concentration, $5.0 \%$ and $2.5 \%$, respectively, $\mathrm{w} / \mathrm{v}$, $\mathrm{pH} 2.90)$, kept overnight $(16 \mathrm{~h})$ at $4^{\circ} \mathrm{C}$, and centrifuged $3,400 \mathrm{~g}$ for 20 in at $4^{\circ} \mathrm{C}$. Most of the ovalbumin was remaining in the supernatant fraction (S1) but some of the ovalbumin was co-precipitated with other proteins. So, the precipitant was dissolved with 4 volumes of distilled water, added with ammonium sulfate and citric acid (final concentration, $2.0 \%$ and $1.5 \%$, respectively, $\mathrm{w} / \mathrm{v}, \mathrm{pH} 3.35$ ) to precipitate egg white proteins except for ovalbumin, and then centrifuge at $3,400 \mathrm{~g}$ for $20 \mathrm{~min}$ at $4^{\circ} \mathrm{C}$. The supernatant (S2) was collected and pooled with the first supernatant (S1).

The pooled supernatant $(\mathrm{S} 1+\mathrm{S} 2)$ was desalted using ultrafiltration unit equipped with a hollow fiber cartridge (30 kDa cut-off size, GE healthcare Bio-Sciences Corp., USA) and concentrated. The desalted supernatant was mainly composed of ovalbumin, but had some impurities (mainly ovotransferrin). The impurities were removed by heating the sample at $70-80^{\circ} \mathrm{C}$ (at $5^{\circ} \mathrm{C}$ interval) for $15 \mathrm{~min}$ and centrifugation at $3,400 \mathrm{~g}$ for $20 \mathrm{~min}$ at $4^{\circ} \mathrm{C}$. The resulting supernatant was lyophilized (Labconco Corp.) and used for yield analysis of ovalbumin. The yield was calculated using the theoretical values of ovalbumin in egg white.

\section{SDS-PAGE}

SDS-PAGE was conducted under reduced conditions using a Mini-Protein II cell (Bio-Rad). Ten percent Trisglycine SDS-polyacrylamide gels with 5\% stacking gel were prepared and Coomassie Brilliant Blue R-250 (Sigma) staining was used (Price and Nairm, 2009). To check the purity of lysozyme and ovalbumin, gel pictures were taken after destaining. The purity of protein was calculated by converting the density of protein bands in the gel picture using the ImageJ software (NIH, USA).

\section{Western blot}

Western blot was carried out using the method of Xie et al. (2002) with some modifications. Ten percent SDSPAGE gels were used for both lysozyme and ovalbumin. After running the gel, proteins were transferred onto a nitrocellulose membrane (Bio-Rad) at $90 \mathrm{~V}$ for $2 \mathrm{~h}$ under controlled temperature. The transferred membrane was blocked with a 5\% skim milk powder solution dissolve in phosphate buffered saline with tween (PBST). To identify lysozyme, the membrane was treated with rabbit polyclonal antibody to lysozyme (Abcam, after 1:10,000 dilutions) and shaken overnight at $4^{\circ} \mathrm{C}$. The membrane was washed 3 times with the PBST solution at 15 min intervals, exposed to Amersham ECL Prime (GE Healthcare, after 1:1 dilution) for $5 \mathrm{~min}$, and then analyzed using a Chemidoc (BioRad). For ovalbumin, anti-ovalbumin antibody (Abcam) was used after diluting to $1: 15,000$ with distilled water and incubated overnight at $4^{\circ} \mathrm{C}$. The membrane was washed 3 times with PBST solution at $15 \mathrm{~min}$ intervals. Rabbit antimouse $\operatorname{IgG}(\mathrm{H}+\mathrm{L})$ conjugated $\mathrm{AP}^{12}$ (Abcam) was used after diluting to $1: 20,000$ as the secondary antibody, incubated $1 \mathrm{~h}$ at room temperature, and analyzed.

\section{Statistical analysis}

Yield and DC-Protein assay data were analyzed using MINITAB 16.0 statistical software. One-way ANOVA was calculated using Tukey's test $(p<0.05)$ to separate means.

\section{Results and Discussion}

\section{Separation of lysozyme using ion exchange resins}

There are many ion exchange resins that can be used to separate lysozyme from egg white (Safarik et al., 2007; Strang, 1984), but carboxymethyl cellulose (CMC) and Ambelite FPC 3500 were tested. Both continuous and batch methods were tested, but batch method was better than the column method for large-scale separation of lysozyme. Between the two resins tested, Ambelite FPC 3500 performed better than CMC: with CMC, only part of the lysozyme in the egg white was trapped and significant amount of lysozyme was still remaining in egg white solution (Fig. 1). DC Protein assay results also indicated that the amount of lysozyme was significantly higher with FPC 3500 than CMC resin (Data not shown). Also, the purity of the lysozyme separated using Amberlite FPC 3500 resin was better than that with CMC (Fig. 1). Another associated issue of using $\mathrm{CMC}$ resin was that the fine particles of 


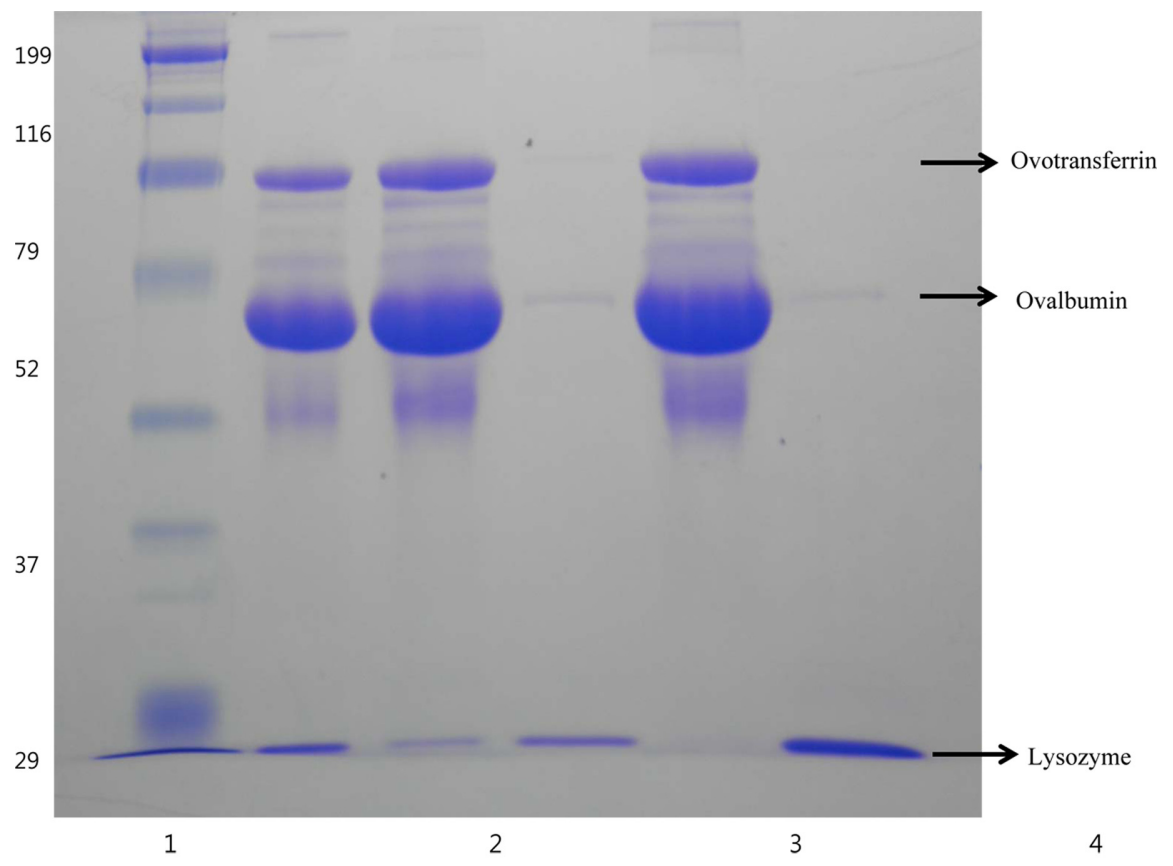

Fig. 1. Comparison of CMC and Amberlite FPC3500 resins to separate lysozyme. Lane 1 = Marker, Lane 2 = Egg white, Lane 3 = Supernatant after removing lysozyme using CMC, Lane 4 = Lysozyme separated using CMC, Lane 5 = Supernatant after removing lysozyme using Amberlite FPC 3500, Lane 6 = Lysozyme separated using Amberlite FPC3500.

CMC floated on the surface of the liquid and resulted in the loss of the resin during the washing steps. The Ambelite FPC 3500 resin had larger granules, which made it easier to handle, and had higher ion exchange capability than CMC. Thus, Ambelite FPC 3500 was selected as a cation exchange resin for lysozyme separation from egg white.

Among the $\mathrm{pH}$ conditions tested ( $\mathrm{pH} 9.0-10.0$ ), equilibration of Amberlite FPC 3500 resin at $\mathrm{pH} 9.3$ produced the best results (data not shown). The binding and release of proteins to and from the ion exchange resin is highly dependent upon $\mathrm{pH}$ of the solution. Because the PI value of lysozyme is 10.7 (Wan et al., 2006), the cation exchange resin should be equilibrated at 1-2 $\mathrm{pH}$ units below the PI of lysozyme. The sample $\mathrm{pH}$ should be adjusted to facilitate the binding of a protein to the resin (Prise and Nairm, 2009). However, the $\mathrm{pH}$ of egg white was not adjusted because its $\mathrm{pH}(9.0-9.5)$ was similar to the equilibration $\mathrm{pH}$ of the resin. Compared with other separation methods for lysozymes such as ammonium sulfate precipitation (Aldertonet al., 1945), CMC (Strang, 1984) and $\beta$-mercaptoethanol with thermal treatment (Chang et al., 2000), cation exchange chromatography using Amberlite FPC 3500 produced higher yields and is more suitable for human use. The theoretical yield of lysozyme separated from $280 \mathrm{~g}$ of egg white is $1.08 \mathrm{~g}$ (egg white contains $11 \%$ protein and $3.5 \%$ of egg white protein is lysozyme) and the lyophilized lysozyme produced was $0.96 \mathrm{~g}$, indicating that the final yield of the lysozyme using the FPC3500 resins method was $88.9 \%$.

\section{Separation of ovalbumin}

Hopkins (1900) first used ammonium sulfate and acid combinations to precipitate ovalbumin, but the method used very high levels of ammonium sulfate in acetic acid. Our previous study showed that low levels of ammonium sulfate in combination with low levels of acetic acid or citric acid removed ovotransferrin effectively (Abeyrathneet al., 2013). So, our approach was leaving ovalbumin in solution instead of precipitating it using ammonium sulfate and acid combinations. We found that addition of citric acids $(2.5 \%, \mathrm{w} / \mathrm{v})$ helped precipitating egg white proteins, especially ovotransferrin, even at low ammonium sulfate concentration $(5 \%, \mathrm{w} / \mathrm{v})$. The reasons for high susceptibility of ovotransferrin to ammonium sulfate under acidic conditions are not clear, but should be related to the changes in the surface charges of ovotransferrin molecules, which changed their interactions with water, solute and other protein molecules. Thus, our approach requires significantly lower levels of ammonium sulfate and acid than that of Hopkins (1900). The performance of ammonium sulfate in combination with citric acid was better than that with acetic acid in precipitating egg white proteins $(70 \mathrm{mg} / \mathrm{mL}$ vs $40 \mathrm{mg} / \mathrm{mL})$ due to unknown rea- 


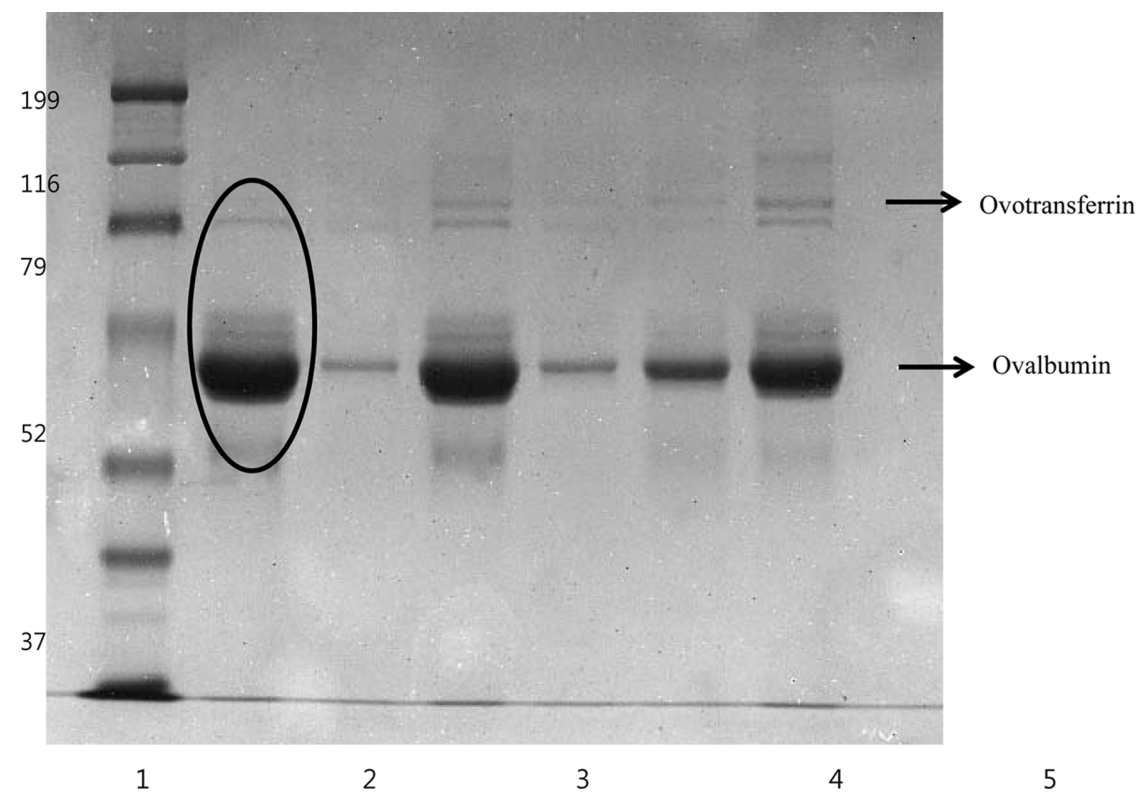

Fig. 2. Effect of heat treatment on the removal of residual proteins from separated ovalbumin. Lane $1=$ Marker, Lane $2=$ Supernatant of $70^{\circ} \mathrm{C}$, Lane $3=$ Precipitant of $70^{\circ} \mathrm{C}$ heat treatment, Lane $4=$ Supernatant of $75^{\circ} \mathrm{C}$ heat treatment, Lane $5=$ Precipitant of $75^{\circ} \mathrm{C}$ heat treatment, Lane $6=$ Supernatant of $80^{\circ} \mathrm{C}$ heat treatment, Lane $7=$ Precipitant of $80^{\circ} \mathrm{C}$ heat treatment.

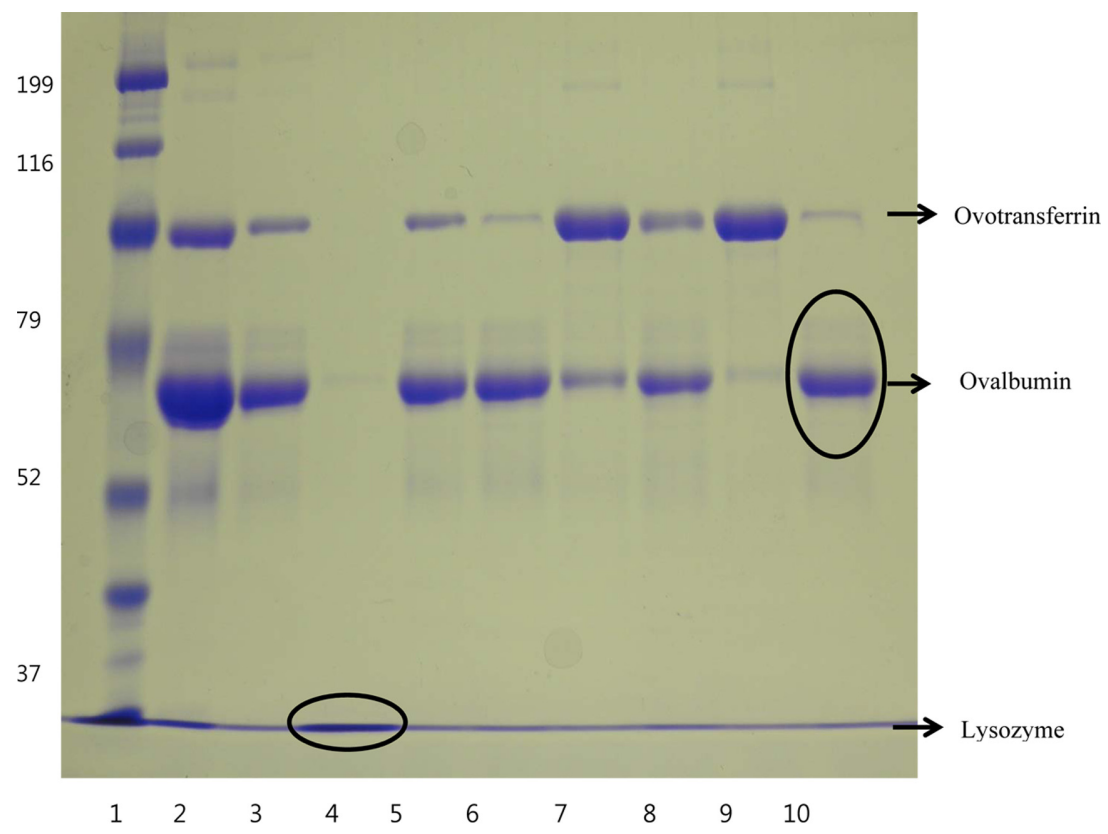

Fig. 3. SDS-PAGE of the samples collected over the sequential separation steps. Lane $1=$ Marker, Lane $2=$ Egg white, Lane $3=$ Egg white after removing lysozyme, Lane 4 = Lysozyme separated, Lane $5=$ Egg white after removing ovomucin, Lane 6 $=$ Supernatant after ammonium sulfate and citric acid precipitation, Lane $7=$ Precipitant of ammonium sulfate and citric acid treatment, Lane $8=$ Supernatant after removing ovotransferrin, Lane $9=$ dissolve precipitant, Lane $10=$ Purified ovalbumin.

sons. So, citric acid was used in the subsequent works. The results of several combinations of citric acid and ammonium sulfate combinations indicated that increasing citric acid levels higher than $2.5 \%$ and ammonium sulfate levels higher than $5 \%$ did not help in separating ovalbumin from the rest of the egg white proteins. DC protein assay results also showed that increasing ammonium sulfate $>5 \%$ and citric acid $>2.5 \%$ in stage I did not help separating ovalbumin from rest of the egg white proteins $(p>0.05)$ (Data not shown). Thus, 2.5\% (w/v) citric 


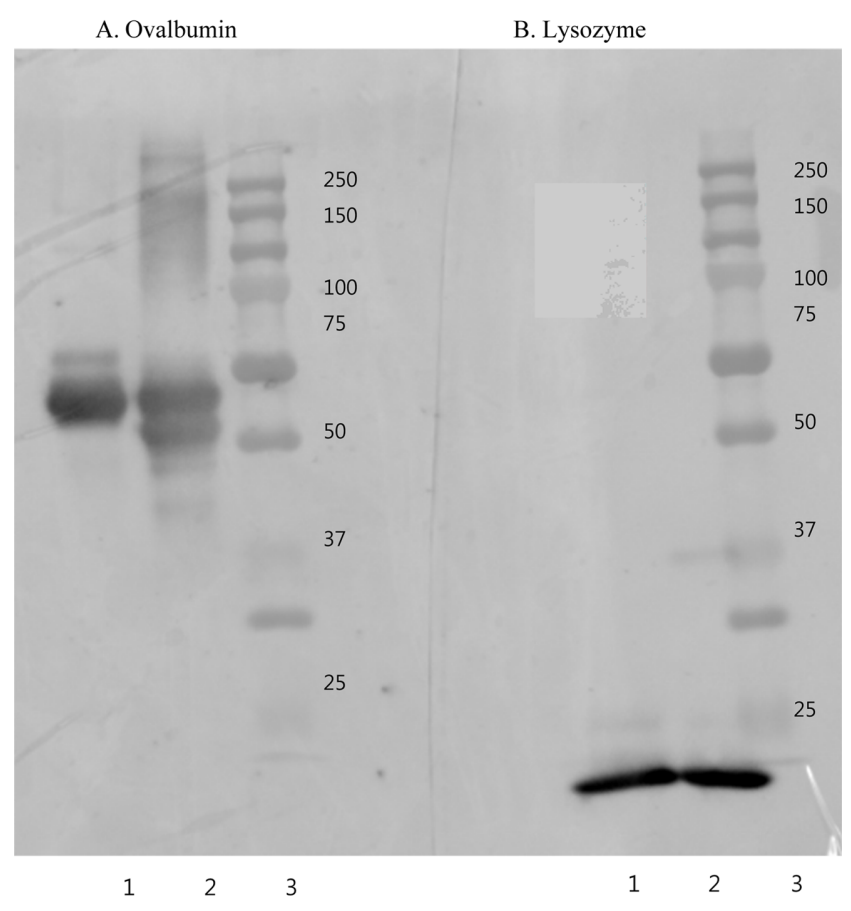

Fig. 4. Western blot of ovalbumin (A: Lane $1=$ Purified ovalbumin, Lane 2 = Standard ovalbumin, Lane 3 = Marker) and lysozyme (B: Lane 1 = Purified lysozyme, Lane 2 = Standard lysozyme, Lane 3 = Marker).

acid and 5\%(w/v) ammonium sulfate combination was used to separate ovalbumin from rest of the egg white proteins after lysozyme is removed. The recovery of ovalbumin using $2.0 \%(\mathrm{w} / \mathrm{v})$ ammonium sulfate and $1.5 \%(\mathrm{w} / \mathrm{v})$ citric acid after dissolving the precipitant with 5 volumes of water (Abeyrathne et al., 2013) helped increasing the yield of ovalbumin significantly.

\section{Further purification of ovalbumin}

To remove the impurities present in the ovalbumin preparation, which are mainly ovotransferrin, heat treatment was added after the desalting and concentration step. The heat treatment results indicated that heating the ovalbumin solution at $70^{\circ} \mathrm{C}$ for $15 \mathrm{~min}$ removed most of the impurities (Fig. 2). Ovotransferrin in the ovalbumin solution was easily removed by the heat treatment because ovotransferrin was highly susceptible to heat denaturation (Stadelman and Cotterill, 2001). Fig. 3 summarizes the sequential separation of lysozyme and ovalbumin using ion exchange and ammonium sulfate and citric acid combinations, respectively. Western blot results confirmed the two proteins separated as ovalbumin (Fig. 4A) and lysozyme (Fig. 4B).

\section{Yield of lysozyme and ovalbumin}

The yield of lysozyme was over $88.9 \%$ and that of oval-
Table 1. Yield of final ovalbumin and lysozyme purified from the treatments

\begin{tabular}{lcc}
\hline \hline Sample & Weight $(\mathrm{g})$ & Yield \% \\
\hline Egg white & & \\
Ovalbumin $^{1}$ & 16.63 & 100 \\
Lysozyme $^{1}$ & 1.08 & 100 \\
Final ovalbumin $^{2}$ & $16.24 \pm 0.75$ & $97.70 \pm 4.47$ \\
Final lysozyme $^{2}$ & $0.96 \pm 0.02$ & $88.90 \pm 1.93$ \\
\hline
\end{tabular}

${ }^{1}$ The calculated amount of ovalbumin and lysozyme in egg white (Protein content in egg white is $11 \%$ of the total egg white. Ovalbumin is $54 \%$ and lysozyme is $3.5 \%$ of the total egg white proteins). The original amount of the egg white used was $280 \mathrm{~g}$ per replication.

${ }^{2}$ Ovalbumin and lysozyme produced. $n=3$.

bumin was over $97.7 \%$ (Table 1). Compared with the yield obtained from the sequential separation of egg white proteins (lysozyme 55\% and ovalbumin 54\%) by Tankrathok et al. (2009) this protocol produced higher yields of lysozyme and ovalbumin. The purity of lysozyme was $>97 \%$ and that of ovalbumin was $>87 \%$.

In conclusion, lysozyme and ovalbumin can be successfully separated in sequence using Amberlite FPC 3500 cation exchange chromatography and ammonium sulfate and citric acid combinations. The yield of the separated lysozyme and ovalbumin was $89.9 \%$ and $97.7 \%$, and the purity was $>87 \%$ for ovalbumin and $>97 \%$, respectively. The protocol is simple and has a high possibility to be scaled up for commercial applications. Fig. 5 summarize

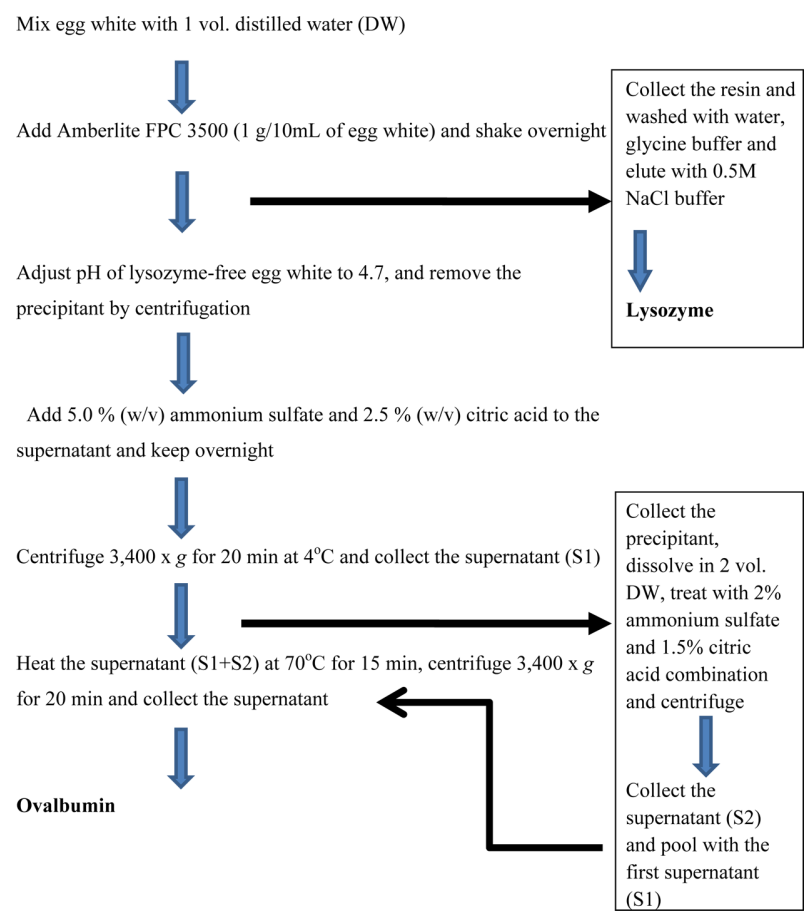

Fig. 5. Schematic diagram for the separation of lysozyme and ovalbumin from egg white. 
the sequence of separation of lysozyme and ovalbumin.

\section{Acknowledgements}

This study was supported jointly by the Cooperative Research Program for Agriculture Science \& Technology Development (Project No. PJ008460) Rural Development Administration, Republic of Korea, and WCU (World Class University) program (R31-10056) through the National Research Foundation of Korea funded by the Ministry of Education, Science and Technology.

\section{References}

1. Abeyrathne, E. D. N. S., Lee, H. Y, Ham, J. S., and Ahn, D. U. (2013) Separation of ovotransferrinfrom chicken egg white without using organic solvents. Poultry Sci. 92, 1091-1097.

2. Alderton, G., Ward, W. H., and Fevold, H. L. (1945) Ioslation of lysozyme from egg white. J. Biol. Chem. 157, 43-58.

3. Awade, A. C. and Efstahiou, T. (1999).Comparison of three liquid chromatography methods for egg-white protein analysis. J. Chromatogr. B, 723, 69-74.

4. Chang, H. M., Yang, C. C., and Chang, Y. C. (2000) Rapid separation of lysozyme from chicken egg white by reductants and thermal treatment. J. Agric. Food Chem. 48, 161-164.

5. Chick, H. and Martin, C. J. (1913).The Precipitation of egg albumin by ammonium sulfate.A contribution to the theory of the "Salting Out" of proteins. Biochem. J. 7, 380-398.

6. Datta, D., Bhattacharjee, S., Nath, A., Das, R., Bhattacharjee, C., and Datta, S. (2009). Separation of ovalbumin from chicken egg white using two-stage ultrafiltration technique. Separ. Purif. Technol. 66, 353-361.

7. Desert, C., Dubiard, C. G., Nau, F., Jan, G., Val, F., and Mallard, J. (2001) Comparison of different electrophoretic separations of hen egg white proteins. J. Agric. Food Chem. 49, 4553-4561.

8. Hopkins, F. G. (1900) On the separation of a pure albumin from egg white. J. Physiol. 25, 306-330.

9. Huopalahti, R., Fandino, R. L., Anton, M., and Schade, R. (2007) Bioactive egg compounds. Springer, NY. pp. 3-66.

10. Manso, M. A., Miguel, M., Even, J., Heranández, R., Aleix- andre, A., and Fandiño, R. L. (2008) Effect of the long-term intake of egg white hydrolysates on the oxidative status and blood lipid profile of spontaneously hypertensive rats. Food Chem. 109, 361-367.

11. Miguel, M. and Aleixandre, A. (2006) Antihypertensive peptides derived from egg proteins. J. Nutr. 136, 1457-1460.

12. Miguel, M., Alonso, M. J., Salaices, M., Aleixandre, A., and Fandiño, R. L. (2007) Antihypertensive, ACE-inhibitory and vasodilator properties of egg white hydrolysates: Effect of a simulated intestinal digestion. Food Chem. 104, 163-168.

13. Mine, Y., Ma, F., and Lauriau, S. (2004) Antimicrobial peptides released by enzymatic hydrolysis of hen egg white lysozyme. J. Agric. Food Chem. 52, 1088-1094.

14. Price, N. C. and Nairn, J. (2009) Exploring proteins: A student's guide to experimental skills and methods. Oxford University Press, pp. 259-278.

15. Radziejewska, R. C., Leœnierowski, G., and Kijowski, J. (2008) Properties and application of egg white lysozyme and its modified preparations-A Review. Polish J. Food Nutr. Sci. 58, 5-10.

16. Safarik, I., Sabatkova, Z., Oldrich, T., and Safarikov, M. (2007) Magnetic cation exchange isolation of lysozyme from native hen egg white. Food Technol. Biotechnol. 45, 355-359.

17. Stadelman, W. J. and Cotterill, O. J. (2001) Egg science and technology. $4^{\text {th }}$ ed. Avi. Publ. Co., Westport, CT.

18. Strang, R. H. (1984) Purification of egg white lysozyme by ion exchange chromatography. Biochem. Edu. 12, 57-59.

19. Tankrathok, A., Daduang, S., Patramanon, R., Arakai, T., and Thammasirirak, S. (2009) Purification process for the preparation and characterization of hen egg white ovalbumin, lysozyme, ovotransferrin and ovomucoid. Prep. Biochem. Biotechnol. 39, 380-399.

20. Wan, Y., Lu, J., and Cui, Z. (2006) Separation of lysozyme from chicken egg white using ultrafiltration. Separ. Purif. Technol. 48, 133-142.

21. Ward, T. M., Edwards, R. A., and Tanner, R. D. (2007) Separating a mixture of egg yolk and egg white using foam fractionation. Appl. Biochem. Biotechnol. 136, 927-934.

22. Xie, H., Huff, G. R., Huff, W. E., Balog, J. M., Holt, P., and Rath, N. C. (2002) Identification of ovotransferrin as an acute phase protein in chickens. Poultry Sci. 81, 112-120.

(Received 2013.5.22/Revised 2013.8.7/Accepted 2013.8.12) 